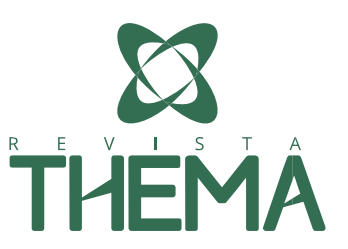

\title{
"Pôr a mão na massa": elaboração, execução e reflexão sobre uma prática de ensino de Geometria na modalidade EJA
}

\section{"Putting the hand in the mass": elaboration, execution and reflection on a teaching practice of Geometry in the EJA}

\author{
Rodrigo Sychocki da Silva ${ }^{1}$; Rodrigo Dalla Vecchia ${ }^{1}$; Lucas Führ ${ }^{1}$
}

\begin{abstract}
RESUMO
O presente artigo tem como finalidade explanar sobre uma experiência de ensino ocorrida numa disciplina da graduação em Licenciatura em Matemática no primeiro semestre de 2017 numa instituição federal de ensino. Como se trata de uma disciplina de caráter teórico-prático, os licenciados devem planejar, executar e refletir sobre uma prática que deve acontecer no nível básico de ensino. Na ocasião o assunto explorado na prática de ensino fora geometria e o público alvo estudantes de ensino médio na modalidade Educação de Jovens e Adultos (EJA). Com a fundamentação teórica ancorada em autores que destacam a proximidade que a matemática deve ter com a realidade dos educandos, aqui se apresenta um recorte teórico-metodológico e reflexivo sobre o constituir-se professor de matemática em formação inicial. Com o estudo é possível inferir que ao aproximar leituras teóricas e reflexões sobre a prática docente, já no curso de graduação, o futuro professor torna-se consciente do seu inacabamento inerente ao fazer docente.
\end{abstract}

Palavras-chave: Aprendizagem. Educação de Jovens e Adultos. Ensino. Formação inicial de professores. Geometria.

\begin{abstract}
This article aims to explain a teaching experience that occurred in a subject of undergraduate degree in Mathematics in the first semester of 2017 in a federal teaching institution. As it is a theoretical-practical discipline, graduates should plan, execute and reflect on a practice that should happen at the basic level of teaching. On the occasion the subject explored in the practice of teaching outside geometry and the target audience high school students in the modality of Youth and Adult Education (EJA). With the theoretical foundation anchored in authors who emphasize the proximity that mathematics should have with the reality of the students, here is presented a theoretical-methodological and reflexive clipping about the constituting teacher of mathematics in initial formation. With the study it is possible to infer that when approaching theoretical readings and reflections on the teaching practice, already in the undergraduate course, the future teacher becomes aware of its incompleteness inherent in teaching.
\end{abstract}

Keywords: Learning. Youth and Adult Education. Teaching. Initial teacher training. Geometry.

\footnotetext{
${ }^{1}$ UFRGS - Universidade Federal do Rio Grande do Sul, Porto Alegre/RS - Brasil
} 


\section{INTRODUÇÃO}

O ensino e a aprendizagem de tópicos de geometria são focos das reflexões e investigações do presente artigo. Temos como objetivo refletir sobre a prática docente no âmbito escolar, especificamente na Educação de Jovens e Adultos (EJA), com foco nos métodos avaliativo e de ensino utilizados na disciplina de Laboratório de Prática de Ensino-Aprendizagem em Matemática II, do curso de Licenciatura em Matemática da Universidade Federal do Rio Grande do Sul (UFRGS).

Tal disciplina constituiu-se num espaço de experimentação docente, que vai desde o planejamento até a execução e reflexão sobre a prática do ensino matemático. Transcorrida no primeiro semestre de 2017, objetivou discutir o ensino e a aprendizagem de tópicos de geometria euclidiana. A prática de ensino aqui explanada foi desenvolvida na disciplina e aplicada em turmas da EJA, e criou oportunidade profícua à reflexão sobre a importância da articulação do binômio "teoria e prática" na exequibilidade do exercício docente.

As reflexões exploraram a importância de mostrar aos estudantes da EJA que a Matemática está inserida em seus cotidianos e, de alguma forma, mostrar a eles que não "gostar" de Matemática, por vezes, está relacionado ao fato de não entender a disciplina, pois, segundo Ponte (1994), para os alunos:

[...] a principal razão do insucesso na disciplina de Matemática resulta desta ser extremamente difícil de compreender. No seu entender, os professores não a explicam muito bem nem a tornam fácil. Assim os alunos não percebem para que ela serve, nem porque são obrigados a estudá-la. Alguns alunos interiorizam mesmo desde cedo uma auto-imagem de incapacidade em relação à disciplina. Dum modo geral, culpamse a si próprios, aos professores, ou às características específicas da Matemática. (PONTE, 1994, p. 2)

A partir do pensamento de Ponte (1994), tem-se como principal intenção, relatar e refletir neste texto, como as atividades envolvendo matemática e cotidiano podem contribuir para a formação dos estudantes da EJA e, também, dos professores em formação envolvidos em tal exercício de docência. Deseja-se mostrar também que, ao explorar a importância de ultrapassar os limites da escola e deixar que as vivências dos alunos e professores se tornem parte do aprendizado dentro da sala de aula, estar-se um currículo para um considerável número de estudantes que não concluíram a educação básica e que tem experiências de vida pertinentes de serem exploradas no âmbito da escola.

Por mais que se tenha almejado tornar a escola moderna universal obrigatória, muitos sujeitos foram e continuam sendo deixados de fora desses espaços. Pessoas que, quando na idade considerada padrão (para estarem dentro da sala de aula), por diversos motivos, sejam eles sociais ou econômicas, foram obrigadas a deixarem o núcleo escolar para trabalhar, ajudar em casa ou por, simplesmente, não se sentirem pertencentes àquele grupo escolar que tinha uma identidade definida.

Pensando nesses estudantes da EJA, as atividades e procedimentos aqui narrados objetivam a apresentar e a discutir uma experiência de ensino ocorrida em três encontros de uma hora e meia cada um, realizados com a turma EM3 - Ensino Médio 3, da "Modalidade de Educação de Jovens e Adultos" do Colégio de Aplicação (CAp) da Universidade Federal do Rio Grande do Sul (UFRGS). 


\section{ARTICULAÇÕES TEÓRICAS NECESSÁRIAS AO EXPERIMENTO}

Segundo as orientações curriculares para o Ensino Médio, o ensino e a aprendizagem são vistos a partir de duas concepções: "[...] uma primeira, historicamente mais presente nas nossas salas de aula de Matemática, identifica ensino como uma transmissão do conhecimento, e a aprendizagem como uma recepção de conteúdos" (BRASIL, 2006, p. 80). Já a segunda, "[...] ainda pouco explorada em nossos sistemas de ensino, transfere ao aluno, em grande parte, a responsabilidade pela sua própria aprendizagem" (BRASIL, 2006, p. 81), e o professor um mediador dos processos de ensino e aprendizagem na construção dos conceitos que podem ser apresentados por meio de situaçõesproblema, fazendo com que o estudante tenha a possibilidade de criar mecanismos próprios para construir conceitos matemáticos.

A partir das práticas em sala de aula, percebe-se que as principais dificuldades dos alunos da escola com respeito à Matemática se referem aos cálculos, regras, símbolos, sinais, algoritmos às regras operacionais e linguagem. Considerando-se tal aspecto, autores como Darsie (1999) apud Neves e Damiani (2006), afirmam que os processos de ensino ainda persistem:

[...] no professor, que organiza as informações do meio interno que deverão ser internalizadas pelos alunos, sendo esses apenas receptores de informações e do seu armazenamento na memória. O modelo de ensino é fechado, acabado, livresco, no qual a noção do conhecimento consiste no acúmulo de fatos e informações isoladas, imerso em simbolismos, quadros cheios de cálculos e fórmulas ou definições a serem memorizadas em significado real. (DARSIE, 1999, apud NEVES e DAMIANI, 2006, p2).

Nessa perspectiva, o estudante é visto como uma folha de papel em branco e receptor de informações, as quais são repassadas de modo predominantemente expositivo. Neste caso, ele tem a obrigação de acumular tais informações na memória. Esse método chamado de "ditatorial", consistia em uma relação de extremo poder, onde o professor decide o que fazer e os alunos executam, o professor ensina e o aluno, pela visão do docente, aprende (BECKER apud NEVES e DAMIANI, 1993, p.2).

Percebe-se que tal pensamento está em consonância com Papert (1994) quando refere-se ao ensino e à aprendizagem de matemática na sala de aula. Para esse autor, a Matemática muitas vezes é um currículo rígido, cujos alunos não podem pensar ou agir de maneira singular. Os discentes são ensinados a seguir um padrão determinado pelo currículo que geralmente, é fechado e desestimula grande parte dos alunos. Para aquele autor, a aprendizagem reside predominantemente ainda em um acúmulo de conhecimentos, e o ensino baseia-se essencialmente na verbalização do conteúdo por parte do professor, desinteressando a maioria dos estudantes dentro de uma sala de aula.

A partir das reflexões de Papert (1994), pensar em escola e, portanto, também em educação, significa focar na ação e, sobretudo, na reflexão dos educandos diante do cotidiano e da sociedade em que vivem, e estabelecer um ritual programado sem que sejam levadas em conta as suas vivências, mostra que o currículo, na maioria das vezes, é rígido e não instiga os estudantes a exercitar o pensamento. Acredita-se que a educação deve ser problematizadora, deve fomentar o pensamento crítico nos alunos, e a ter consciência de suas decisões. Assim, o professor é visto como um mediador, auxiliando no processo de construção do conhecimento e gerando oportunidades de elaboração de conceitos, dedução de fórmulas, desenvolvimento do raciocínio lógico e relações entre os objetos do conhecimento. 
Ao olhar para a matemática, em especial para a Geometria Plana, constata-se que a mesma está presente em diferentes campos da vida humana, seja nas construções, nos elementos da natureza ou nos objetos que utilizamos. Por esse motivo, os Parâmetros Curriculares Nacionais (BRASIL, 1998) e os pesquisadores da área da Educação Matemática, de modo geral, recomendam que a escola proporcione aos seus partícipes o estudo desse conhecimento, visando a sua compreensão do mundo em que vivem e a sua interação com ele (GÁLVEZ, 1996), possibilitando, assim, um maior entendimento da realidade que cerca os estudantes. Levando-se isso em consideração, as Orientações Curriculares para o Ensino Médio afirmam que:

[...] o estudo da Geometria deve possibilitar aos alunos o desenvolvimento da capacidade de resolver problemas práticos do quotidiano como, por exemplo, orientarse no espaço, ler mapas, saber comparar distâncias percorridas, reconhecer propriedades de formas geométricas básicas, saber usar diferentes unidades de medida. Também é um estudo em que os alunos podem ter uma oportunidade especial, com certeza não única, de apreciar a faceta da Matemática que trata de teoremas e argumentações dedutivas. (BRASIL, 2006, p. 75)

Entende-se que aprender geometria por meio de experiências do cotidiano pode propiciar aos alunos, novas experiências matemáticas, valendo-se de todo o ambiente escolar. Com o exercício do pensamento geométrico aliado à construção de conceitos matemáticos pode-se criar possibilidades para o desenvolvimento intelectual dos envolvidos. Na geometria, para onde quer que se direcione o olhar, representações geométricas podem ser reconhecidas nos planos bidimensional e tridimensional, sejam na natureza, nas artes ou em outras áreas do conhecimento.

Segundo a Base Nacional Comum Curricular (BRASIL, 2017), a área de geometria não pode ser limitada à aplicação de fórmulas de área e volume, muito menos de fórmulas algébricas imediatas de teoremas, ela precisa passar por um processo de construção dos conceitos cujo trabalho entre aluno e professor deve ser coletivo. Os Parâmetros Curriculares Nacionais ( $\mathrm{PCN}+$ ) reafirmam que a geometria:

[...] não se trata da memorização de um conjunto de postulados e de demonstrações, mas da oportunidade de perceber como a ciência Matemática valida e apresenta seus conhecimentos, bem como propiciar o desenvolvimento do pensamento lógico dedutivo e dos aspectos mais estruturados da linguagem matemática (BRASIL, 2002, p. 124)

A partir do trabalho coletivo entre professor e estudantes, o desenvolvimento do pensamento lógicodedutivo pode ser construído por meio de atividades envolvendo diferentes recursos dentro de sala de aula. Neste contexto, o professor pode criar cenários para investigação, que são ambientes que podem dar suporte a um trabalho de investigação, para instigar os estudantes a se depararem com propriedades matemáticas. Contudo, esse cenário só se concretiza se os discentes aceitam o convite para nel trabalhar. O cenário para investigação é considerado uma propriedade relacional, pois essa pode ser aceita por um grupo de sujeitos, e rejeitada por outro, como diz Skovsmose (2000):

A aceitação do convite depende de sua natureza (a possibilidade de explorar e explicar propriedades matemáticas de uma tabela de números pode não ser atractiva para muitos alunos), depende do professor (um convite pode ser feito de muitas maneiras e para alguns alunos um convite do professor pode soar como um comando), e depende, certamente, dos alunos (no momento eles podem ter outras propriedades). (SKOVSMOSE, 2000, p. 6) 
Uma prática em sala de aula pode ser baseada na construção de ambientes de aprendizagem para que o estudante possa compreender melhor o conteúdo, seja usando o paradigma do exercício ou o paradigma de cenários de investigação. Skovsmose (2000) fala que é possível se apoiar em três tipos de referência na construção desses ambientes de aprendizagem.

Primeiro, questões e actividades matemáticas podem se referir à matemática e somente a ela. Segundo, é possível se referir a uma semi-realidade; não se trata de uma realidade que "de facto" observamos, mas uma realidade construída, por exemplo, por um autor de um livro didáctico de Matemática. Finalmente, alunos e professores podem trabalhar com tarefas com referências a situações da vida real. (SKOVSMOSE, 2000, p.7)

Para exemplificar melhor a relação entre os dois paradigmas e essas três referências, o autor apresenta um quadro, conforme mostrado a seguir, que ilustra seis tipos diferentes de ambientes de aprendizagem.

\begin{tabular}{|c|c|c|}
\hline & Exercícios & Cenários para Investigação \\
\hline Referências à matemática pura & $(1)$ & $(2)$ \\
\hline Referências à semi-realidade & $(3)$ & $(4)$ \\
\hline Referências à realidade & $(5)$ & $(6)$ \\
\hline
\end{tabular}

Tabela 1: Referências e Cenários para Investigação. Fonte: SKOVSMOSE, 2000, p. 8.

O ambiente do tipo (1) se refere a exercícios diretamente relacionados à matemática como, por exemplo, efetue a seguinte expressão algébrica, calcule as divisões abaixo, etc. É um ambiente em que o estudante reproduz mecanicamente diversos exercícios a fim de memorizar o método.

O ambiente do tipo (2) é caracterizado como um cenário para investigação da matemática pura. É um ambiente que "envolve números e figuras geométricas. O exemplo introdução da translação de figuras geométricas numa tabelas de números ilustra esse tipo de ambiente" (SKOVSMOSE, 2000, p.8).

O ambiente do tipo (3) faz referência a exercícios relacionados a semi-realidade. Podemos dizer que são as famosas "historinhas matemáticas". Como exemplo tem a seguinte questão: "Um feirante ' $A$ ' vende maçãs por $\mathrm{R} \$ 0,85$ o $\mathrm{Kg}$. Por sua vez, o feirante ' $B$ ' vende $1,2 \mathrm{Kg}$ por $\mathrm{R} \$ 1,00$. (a) Que feirante vende mais barato? (b) Qual é a diferença entre os preços cobrados pelos dois feirantes por $15 \mathrm{Kg}$ de maçãs?" (SKOVSMOSE, 2000, p. 8, adaptado). Podemos perceber que esse tipo de ambiente não faz alusão a nenhuma pesquisa por parte do professor para a construção deste exercício. Mesmo que ele fale de maçãs, compra e venda, esta é uma realidade inventada e imaginada pelo docente. Neste ambiente, as informações contidas no exercício são suficientes para a resolução do mesmo, não se preocupando com futuros questionamentos relacionados.

O ambiente do tipo (4), mesmo referindo-se à semi-realidade, como o (3), se diferencia dele, pois, o exercício, embora esteja inserido em uma realidade inventada pelo professor, abre espaço para que o aluno possa questionar sobre ele. Retomando o exemplo usado no ambiente do tipo (3), o estudante pode questionar sobre a qualidade das maçãs, a capacidade do comprador em carregar os $15 \mathrm{~kg}$ mencionados no exercício, qual é a situação econômica da pessoa e se ela tem condições de comprar 
a quantidade indicada. É um cenário para investigação que vai além das informações citadas pelo exercício.

O ambiente do tipo (5) refere-se à realidade, mas voltado apenas ao paradigma do exercício. $\mathrm{O}$ professor convida o estudante a resolver exercícios voltados a realidade como, por exemplo, desemprego, machismo, homofobia, fazendo com que o aluno questione e pense sobre o assunto. Contudo, ele não se aprofunda nas investigações em relação aos assuntos propostos pelo professor, pois, a informação vem pronta na forma de gráficos, notícias de jornais e afins.

O ambiente do tipo (6) é o que mais nos interessa, neste artigo, pois ele se refere à realidade na forma de investigação. Neste tipo de ambiente, a realidade dos estudantes está muito presente nas investigações, pois, aproxima o discente do seu próprio cotidiano e faz entender o contexto socioeconômico e cultural no qual está inserido. Embora seja pouco explorado, dentro de sala de aula, acreditamos que este ambiente de aprendizagem é muito rico para as formações docente e discente desafiando, assim, a tradição da matemática escolar.

A proposta de cenários para investigação, e a aceitação, ou não, dos estudantes, vai ao encontro com o que as diretrizes falam sobre uma educação cooperativa. Trata-se de um trabalho coletivo que resulta na criação de cenários propostos pelo professor ao longo da execução de uma proposta metodológica de ensino. Isso faz com que o estudante consiga conduzir sua própria aprendizagem a um caminho com descobertas e redescobertas. Com isso, acredita-se que o estudante consiga perceber que a matemática pode ajudá-lo a desenvolver uma reflexão sobre a importância dessa para a sociedade. Portanto, nota-se que os cenários para investigação propiciam, dentro de um espaço escolar, o desenvolvimento de uma matemática que fomente o pensar e agir sobre estruturas tecnológicas, militares, econômicas e políticas.

A fim de que tais percepções sejam notadas, os cenários para investigação tornam-se contratos didáticos entre educador e educando. Contudo, tais contratos podem ser quebrados, e existem fatores para que isso aconteça, pois, um contrato didático não é sinônimo de uma aprendizagem de qualidade, mas "indica que o professor e o estudante compartilham a mesma compreensão e aceitação das prioridades do ambiente de aprendizagem" (Skovsmose, 2000, p.16). A quebra de contrato didático, na visão do docente, é um movimento de migração de uma zona de conforto para uma zona de risco levando-o para um novo ambiente de aprendizagem, cujos desafios são maiores, elevando o nível de incertezas e discordâncias entre os envolvidos no processo didático, tal como preconiza Borba e Penteado (2016).

\section{MATERIAIS E MÉTODOS: AS ATIVIDADES DESENVOLVIDAS}

Os primeiros encontros da disciplina de Laboratório de Prática de Ensino-Aprendizagem em Matemática II foram destinados às discussões acerca das geometrias plana, espacial e analítica e, aliado a estas, reflexões sobre a formação inicial de professores e a carreira docente. Ocorreu também a divisão da turma em grupos de trabalho para planejar e elaborar os encontros do experimento de prática de ensino.

Ainda no período de estudo, acredita-se que a discussão e preparação dos planos de aula, contribuíram no percurso formativo de todos os professores envolvidos, os quais foram desenvolvidos um olhar crítico sobre como e o quê ensinar, questionando, sempre que necessário, nossos atos, 
dando dicas sobre como ensinar determinado conteúdo, discussão sobre caminhos alternativos para resolver algum exercício e, acima de tudo, propiciando um amadurecimento pessoal e coletivo.

Todos os materiais didáticos e planos de aula produzidos ao longo das aulas de estudo e discussões, foram enviados aos professores da disciplina que os corrigiam e nos retornavam com questionamentos, apontamentos acerca da prática docente e sugestões, com o objetivo de aperfeiçoar o planejamento do trabalho. Assim que o plano de aula era entendido como construído e pronto para ser executado, era enviado à professora titular das turmas da EJA do Colégio de Aplicação da UFRGS (CAp), que o analisava, e nos dava um "feedback" sobre as atividades propostas.

A prática de ensino realizada ocorreu na turma do EM3 do CAp, cujos conteúdos de Geometria Plana e Espacial abordados foram:

Geometria Plana: diferenciar os três tipos de ângulos (agudo, obtuso e reto); características de quadriláteros retos, triângulos e círculos; cálculo da área e perímetro dos quadriláteros retos; cálculo da área e perímetro de triângulos; cálculo de área e perímetro de círculos; estimular a percepção da geometria plana no mundo físico.

Geometria Espacial: cálculo do volume do cubo; cálculo do volume do prisma de base triangular e retangular; cálculo do volume do cilindro; estimular a percepção da geometria espacial no mundo físico.

No primeiro encontro, começamos a abordar o conteúdo de figuras geométricas e em especial, quadrado, retângulo, triângulo e círculo. O principal objetivo fora fazer com que os estudantes conseguissem visualizar as diferenças entre as figuras geométricas, o desenho que representava cada uma delas e como obter as características de áreas e perímetros. Na ocasião da execução da prática pedagógica, éramos um grupo de oito professores lecionando, então se fez a divisão em duplas, e cada dupla de professores ficou responsável por explorar uma figura geométrica. A dupla de professores questionava na abordagem onde se podia encontrar tal figura no cotidiano e estabelecia relações com as demais, finalizando a explicação com um exercício teórico sobre área e perímetro.

Iniciou-se o segundo encontro com a revisitação às figuras geométricas que foram apresentadas no encontro anterior e neste, apresentamos o círculo, pois não fora possível fazer o diálogo sobre ela no primeiro encontro. Ao iniciar-se a segunda aula abordando a forma do círculo, questionaram-se quais eram as principais diferenças do círculo para as outras figuras, debatendo-se sobre área e perímetro.

Os estudantes também precisaram de tempo para entender o processo de construção das relações para o cálculo de área e comprimento e, depois de vários exemplos e discussões, percebe-se que o entendimento do significado de cada termo das fórmulas e como aplicá-las faria mais demandavam uma segunda parte da aula. No segundo momento da aula, cada dupla de professores ficou com um grupo de alunos e saímos da sala para procurar pela escola quadrados, retângulos, triângulos e círculos. A tarefa consistia em medir os lados dos polígonos ou comprimento dos círculos, levar para dentro da sala aula e calcular a área e o perímetro daquelas formas geométricas encontradas, nas imediações da escola.

No terceiro e último encontro, revisitamos as relações matemáticas de área e perímetro com a turma e, logo em seguida, abordamos o conceito de volume dos poliedros. Após, solicitamos à turma que se organizassem nos mesmos grupos da aula anterior, e que em uma atividade fora da sala de aula 
medissem objetos que tivessem a forma de algum poliedro ou cilindro. Os estudantes, tal como na aula anterior, se mostraram empenhados para realizar a atividade, pois novamente eles iriam pôr em prática as fórmulas e relações para o cálculo de volume.

\section{ANÁLISES PÓS-EXPERIÊNCIA: UM OLHAR NO PROCESSO}

Destacamos de início que durante o semestre trabalhar em coletivo, estudando, organizando materiais didáticos e planejando aulas investigativas e, ao mesmo tempo, dessem conta da demanda de dificuldade que os estudantes da EJA tenha sido um exercício constante de autoconhecimento e paciência, visto que trabalho coletivo nem sempre se mostra fácil de executar.

Ao longo do primeiro encontro, na turma EM3 da EJA, tinha-se como principal objetivo fazer com que os estudantes conseguissem visualizar as diferenças entre as figuras geométricas quadrado, retângulo, triângulo e círculo, os desenhos que as representassem correspondentemente e como calcular suas áreas e perímetros. De acordo com o quadro de Skovsmose (2000) sobre ambientes de aprendizagem, podemos perceber que o ambiente do tipo (1) ficou bem evidente, nesta aula, visto que a mesma foi expositiva e conceitual, seguida de exercícios teóricos em que os alunos não precisavam investigar ou fazer questionamentos. Tratou-se da reprodução do conteúdo que havia sido passado no quadro.

De forma a não invalidar o método dito "tradicional de ensino", voltado predominantemente ao paradigma do exercício, enfatiza-se que para uma turma da modalidade de Educação de Jovens e Adultos, o trabalho colaborativo, direcionado ao cotidiano dos alunos se mostra mais profícuo para a aprendizagem dos mesmos que chegam à escola, pois os mesmos têm uma bagagem de ricas experiências e que podem ser exploradas ao longo das aulas.

No segundo encontro, continuando-se com a discussão sobre as figuras geométricas de maneira expositiva, focalizou-se no círculo. O método de ensino inicialmente estava voltado para o ambiente de aprendizagem do tipo (1) de Skovsmose, contudo, os estudantes sentiram muita dificuldade em entender a aplicação das fórmulas e nos vimos obrigados a mudar o método de ensino para que eles pudessem entender a relação das variáveis da fórmula de área com a figura geométrica.

No segundo momento do encontro, cada dupla de professores ficou com um grupo de alunos e saímos da sala para procurar quadrados, retângulos, triângulos e círculos. A tarefa consistia em obter medidas sobre polígonos e círculos que fossem necessárias para o cálculo de perímetros e áreas. Após a coleta das medidas os estudantes voltaram para a sala aula com o objetivo de calcular a área e o perímetro daquelas formas geométricas encontradas pelo espaço da escola.

Nesse momento da aula notamos que os alunos tiveram dificuldades em utilizar as fórmulas com os números obtidos por meio das medições, principalmente no cálculo de área e comprimento do círculo, pelo fato de terem que trabalhar com o número pi. Percebemos também que, levar os estudantes para fora da sala de aula e mostrar na prática como as fórmulas são utilizadas em objetos e situações reais, teve um significado importante na aprendizagem dos discentes, pois vimos motivação em suas expressões e empenho em obter a um resultado final, mesmo com dificuldade e pedindo ajuda diversas vezes. 
No terceiro e último encontro, com a abordagem dos conceitos de volume dos cubos, tetraedros, pirâmides (de base triangular) e cilindro, revisitamos todas as fórmulas de áreas e perímetros das figuras planas já abordadas, sempre refletindo e questionando os estudantes sobre onde eles poderiam encontrar poliedros no seu cotidiano. Tal como no encontro anterior, os estudantes saíram da sala de aula para procurar objetos, nas mediações da escola, que tinham os formatos dos poliedros estudados e, dentro da sala de aula, por meio das fórmulas estudadas. O objetivo fora obter informações relativas ao volume dos sólidos.

Os estudantes se mostraram empenhados para realizar a atividade, pois novamente eles iriam pôr em prática as fórmulas que foram apresentadas para o cálculo de volume. Contudo, a dificuldade em utilizar as fórmulas continuava e, por consequência, cada dupla de professores acompanhou um grupo de estudantes desde a coleta das informações até os cálculos realizados em sala de aula. Na figura seguinte, apresentamos os registros fotográficos referentes aos encontros com a turma EM3.
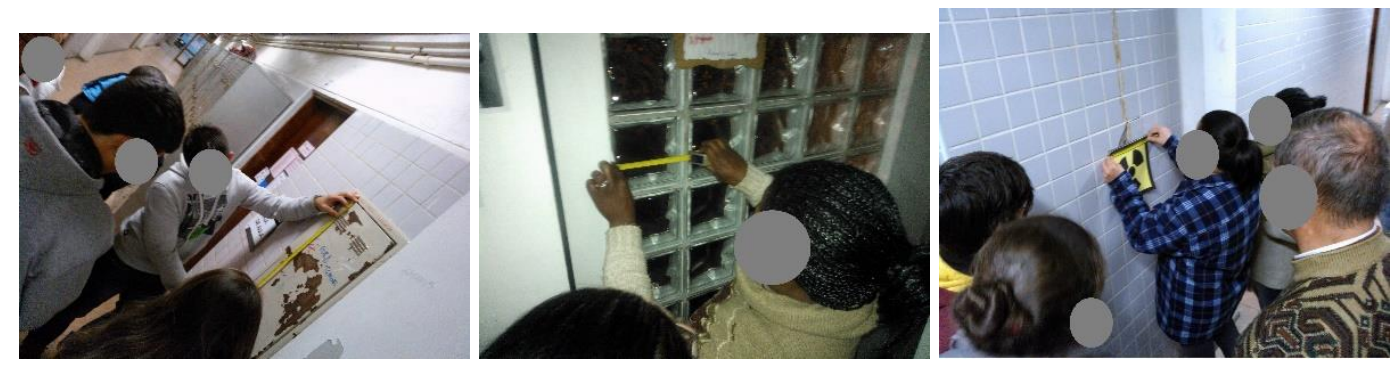

Figura 1: Montagem com fotos das aulas de matemática.

Fonte: Arquivo pessoal (2017).

Ao final dos encontros, pode-se afirmar que a relação dos conteúdos matemáticos com o cotidiano dos estudantes, principalmente dos que participaram desse experimento de ensino foi fundamental para uma aprendizagem, mesmo que apresentando dificuldades. Nossa reflexão tem relação com as reflexões de Bueno e Pires (2013) que propõe:

No percurso curricular não há como prever qual caminho será o mais interessante, pois à medida em que os conteúdos são apresentados, é por meio da interação com os alunos que o professor identifica em quais momentos os alunos apresentam maiores dificuldades. Essa interação é imprescindível para que ocorra o sucesso no processo ensino aprendizagem e no tocante aos alunos jovens e adultos consideramos que o currículo de Matemática para a EJA deve levar em consideração as características e necessidades dos alunos que compõem essa modalidade de ensino, possibilitando uma prática educativa coerente com a realidade cultural de seus educandos. (BUENO e PIRES, 2013, p.26)

Percebe-se que, por meio dos relatos dos próprios estudantes e suas explicações, sempre relacionadas com situações que eles vivem foram do ambiente escolar, seja em seu trabalho ou em casa, e que contribuíram para o enriquecimento das discussões e realização dos exercícios, dentro de sala de aula. Em suma, o experimento de ensino que envolveu o estudo da geometria por estudantes da EJA demonstrou-se um importante exercício reflexivo também para os professores em formação inicial, partícipes no momento de prática docente. 


\section{CONSIDERAÇÕES FINAIS}

Por meio da prática, fica evidente de acordo com os referenciais teóricos considerados que estabelecer uma relação entre a matemática escolar e o cotidiano dos alunos é importante para a aprendizagem significativa dos mesmos. Os estudantes se sentiam motivados a participar das atividades sempre que o conteúdo ultrapassava as paredes da sala de aula e ia além das práticas de ensino que eles estavam cotidianamente acostumados.

Constata-se que a articulação entre teoria e prática envolvida na disciplina de graduação e exposta aqui no texto foi um fator determinante para a reflexão sobre a prática de ensino que ocorreu. $A$ partir da prática observou-se a necessidade de entendimento e reflexão sobre a teoria estudada, com o objetivo de qualificar e aperfeiçoar o fazer didático. Logo, o nível de trabalho ocorrido na disciplina de Laboratório de Prática de Ensino-Aprendizagem em Matemática II, nos momentos de estudo e reflexão sobre a prática docente, colaboraram para a formação inicial dos licenciandos.

Portanto, conclui-se que a criticidade em relação à elaboração de planos de aula e produções escritas deva ser um ponto de reflexão na formação inicial de professores de matemática. Os planejamentos e a prática de ensino devem perpassar um processo que relacione a teoria com o fazer docente, a fim de que o futuro professor de matemática seja um observador, questionador, reflexivo e interventor nos fenômenos observados que ocorrem nas aulas. Para isso, é importante que desde a formação inicial seja necessário por parte do futuro professor que internalize e transforme em aprendizado todo período de elaboração, execução e reflexão da prática docente, que ocorrem desde as disciplinas da graduação.

\section{REFERÊNCIAS}

BECKER, Fernando. Modelos Pedagógicos e Modelos Epistemológicos. Porto Alegre. Paixão de prender, n.5. 1993.

BORBA, Marcelo de Carvalho; Miriam Godoy Penteado. Informática e Educação Matemática. $5^{\circ}$ Edição. 2a Reimpressão. Belo Horizonte. Editora Autêntica. Coleção Tendências em Educação Matemática. 2016.

BRASIL. Ministério da Educação e do Desporto/ Secretaria de Educação Fundamental. Parâmetros Curriculares Nacionais. Brasília: MEC/SEF, 1998.

BRASIL. Ministério da Educação/ Secretaria de Educação Média e Tecnológica. PCN + Ensino médio: orientações educacionais complementares aos Parâmetros Curriculares Nacionais Ciências da Natureza, Matemática e suas Tecnologias. Brasília: MEC/SEMTEC, 2002.

BRASIL. Ministério da Educação e do Desporto/ Secretaria de Educação Básica. Orientações Curriculares para o Ensino Médio. Brasília: MEC/SEB, v. 2, 2006.

BRASIL, Ministério da Educação e do Desporto/ Secretaria de Educação Básica. Base Nacional Comum Curricular. Terceira versão revista, Brasília: MEC/SEB, 2017.

BUENO, Simone; PIRES, Célia Maria Carolino; O Currículo Enculturador de Matemática na EJA. Educação Matemática e Pesquisa, São Paulo, v.2, n.1, p. 14-26, 2013. 
DARSIE, Marta Maria Pontin. Perspectivas Epistemológicas e suas Implicações no Processo de Ensino e de Aprendizagem. Cuiabá, Uniciências, v3: 9-21. 1999.

GÁLVEZ, Grécia. Geometria, a psicogênese das noções espaciais e o ensino da Geometria na escola primária. In: PARRA, Cecília, SAIZ, Irma (Org.). Didática da Matemática: reflexões psicopedagógicas. Tradução de Juan Acuña Lorens. Porto Alegre: Artes Médicas, 1996. p. 236-258.

NEVES, Rita de Araújo; DAMIANI, Magda Floriana. Vygotsky e as teorias de aprendizagem. UNIrevista, São Leopoldo, v. 1, n. 2, abril/2006. Disponível em: <http://www.miniweb.com.br/educadores/Artigos/PDF/vygotsky.pdf>. Acesso em 15 de maio de 2017.

PAPERT, Seymour. A Máquina das Crianças. Repensando a Escola na Era da Informática. Porto Alegre. Artmed. p. 38-55. 1994.

PONTE, João Pedro da. Matemática: uma disciplina condenada ao insucesso. NOESIS, n. 32, p. 24- 26, 1994. Disponível em: <http://www.educ.fc.ul.pt/docentes/jponte/docs-pt/94>. Acesso em: 12 set. 2017.

SKOVSMOSE, Ole. Cenários de Investigação. Bolema, v.13, n. 14, p. 66-91, 2000. 